\section{European \\ Child + Adolescent \\ Psychiatry}

DOI: $10.1007 / \mathrm{s} 00787-008-1000-5$

\title{
Mental health in children and adolescents
}

Results of the BELLA study in Germany

\section{Guest Editors:}

Prof. Dr. Ulrike Ravens-Sieberer

Dr. Bärbel-Maria Kurth

Prof. Dr. Hans-Ulrich Wittchen

Prof. Dr. Aribert Rothenberger

Prof. Dr. Michael Schulte-Markwort

Disclosure: The print of this supplement was financially supported by the Robert Koch-Institute, Berlin, Germany, the University Medical Center Hamburg - Eppendorf, Germany, the Technical University Dresden, Germany, the University Medicine Göttingen, Germany 